\title{
Description of the Immature Stages of Paracantha gentilis (Diptera: Tephritidae)
}

\author{
DAVID HEADRICK AND RICHARD D. GOEDEN
}

Department of Entomology, University of California, Riverside, California 92521

\begin{abstract}
Ann. Entomol. Soc. Am. 83(2): 220-229 (1990)
ABSTRACT Descriptions are provided of the egg, larvae, and puparium of Paracantha gentilis Hering, a native, stenophagous tephritid which infests the capitula of thistles. Detailed examination of larvae led to the discovery of a median oral lobe between the mouth hooks. This is the first structure of this kind described for Tephritidae. Two sensory structures on the anterior lobes of $P$. gentilis also were discovered, the lateral sensory organ and the pit sensory organ. In comparing the anterior sensory apparatus of $P$. gentilis larvae with those in Anthomyiidae, Calliphoridae, Drosophilidae, Muscidae, and Syrphidae, striking similarities were apparent. Photographs that illustrate the development of the spiracular system of the puparial stage are the first offered for a nonfrugivorous tephritid.
\end{abstract}

KEY WORDS Insecta, mouth hooks, sensory organs, Cirsium

THIS STUDY is an outgrowth of faunistic surveys (Goeden \& Ricker 1986) of the thistles Cirsium californicum Gray and C. proteanum J. T. Howell. In this report, we describe the morphology of the heretofore undescribed immature stages of Paracantha gentilis Hering; subsequent papers will treat its biology and ecology.

\section{Materials and Methods}

All immature stages were dissected from capitula of C. californicum collected at Mill Creek, San Bernardino National Forest, San Bernardino Co., Calif. from 25 April to 5 June 1987, and C. proteanum capitula collected from Sawmill Mt., Angeles National Forest, Los Angeles Co., Calif., on 29 July 1987. Eggs used to study eclosion were placed on filter paper soaked with Ringer's solution in covered glass Petri dishes and held in darkened growth chambers at $27^{\circ} \mathrm{C}$. Other eggs and larvae were preserved in $70 \% \mathrm{EtOH}$ for later examination. Puparia were dissected from heads, air-dried, then stored in capped, 6-ml glass shell vials.

In preparation for scanning electron microscopy, all soft-bodied specimens were sonicated $20 \mathrm{~min}$. Eggs were dehydrated to $95 \%$ EtOH overnight, placed in $100 \% \mathrm{EtOH}$ for $5 \mathrm{~min}$, and fixed in hexamethyldisilizane (Nation 1983). Larvae were placed in $2.5 \%$ glycerol and serially saturated to $100 \%$ glycerol (Sher \& Bell 1975) or rehydrated through graded alcohols to distilled water, and fixed in osmium tetroxide for $24 \mathrm{~h}$ (Sabatini et al. 1963). All specimens were mounted on stubs and coated with a gold-platinum alloy. The scanning electron microscope used was a JEOL-JSM-35C3 in the Department of Nematology, University of California, Riverside. Specimens were examined and micrographs were prepared at $15 \mathrm{kV}$ accelerating volt- age, except for specimens in glycerol which were studied at $10 \mathrm{kV}$. Micrographs were prepared with Polaroid $55 \mathrm{P} / \mathrm{N}$ film.

Third instars were dissected in $70 \% \mathrm{EtOH}$ with $0.1 \%$ acid fuchsin for viewing the median oral lobe.

Voucher specimens of $P$. gentilis are stored in the tephritid collection of the second author. This collection will eventually be offered for incorporation into the insect collection of the Department of Entomology, University of California, Riverside.

\section{Results}

Egg. The body of the newly laid egg is smooth, white, elongate (about four times longer than wide), slightly curved, and tapered posteriorly to a bluntly rounded point (Fig. 1). The anterior end is drawn into a long (about 2.5 times length of egg body), opaque-white pedicel with the apex slightly swollen and bearing the honeycombed, aeroscopic plate (Fig. 2). The bodies and pedicels of 45 eggs averaged $1.13 \pm 0.006 \mathrm{~mm}(\bar{x} \pm \mathrm{SE})$ and $2.79 \pm 0.022$ $\mathrm{mm}$ in length, respectively. One pedicel measured $0.03 \mathrm{~mm}$ wide along most of its length, and the tip was $0.07 \mathrm{~mm}$ wide. Paracantha culta (Wiedemann), $P$. forficula Benjamin (Benjamin 1934), and $P$. cultaris (Coquillett) (Cavender \& Goeden 1984) also have eggs with elongate pedicels.

Scanning electron micrographs of the egg at $860 \times$ (Fig. 2) showed the chorion is smooth and lacking reticulation but is studded with many stellate microbodies distributed randomly along the egg body and pedicel. These bodies were plant pollen that had become attached to the egg during oviposition.

The eggs of $P$. gentilis are deposited either singly or in clusters of up to 13 by individual females at one time into immature heads of C. californicum. The body of the egg was usually situated lengthwise 

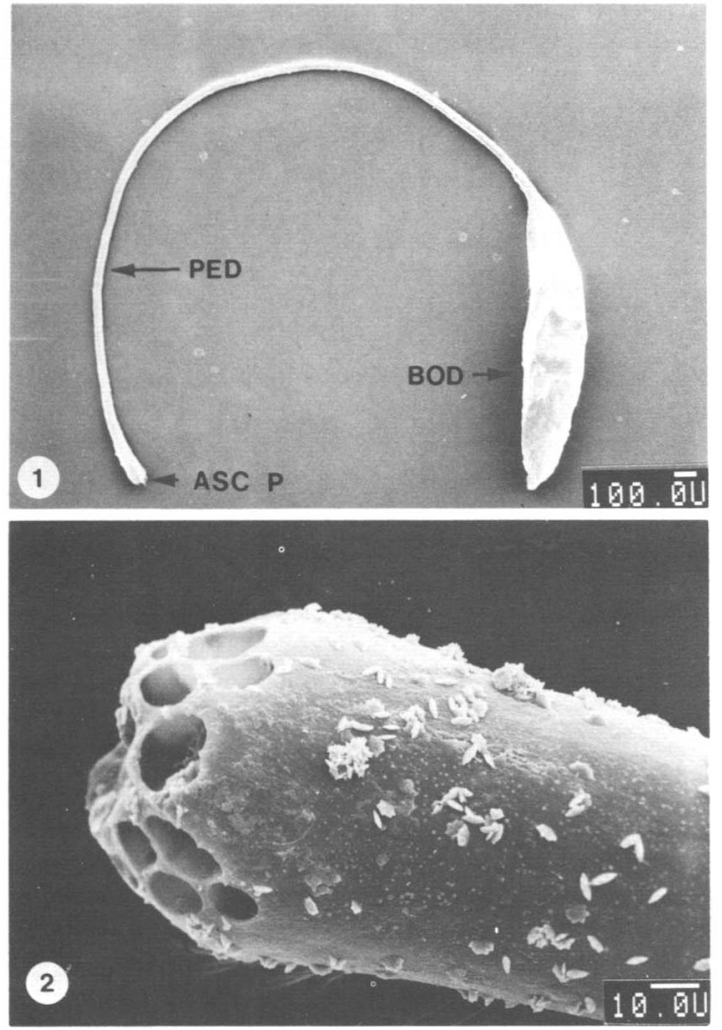

Fig. 1 and 2. (1) Egg of $P$. gentilis. BOD, body; PED, pedicel; ASC $P$, aeroscopic plate $(27 \times)$. (2) Aeroscopic plate $(585 \times)$.

and parallel to the immature florets and above the level of the achenes. Pedicels were mostly within the head, only their tips projecting between the apices of the phyllaries, or within the space between the tops of the florets and the innermost layer of bracts. Other eggs were deposited between the phyllaries or in cavities gouged by the female ovipositor in individual bracts. The pedicel tip was always exposed to the outside air, presumably to facilitate respiration of the developing embryo.

Eggs were collected in the field over a 2-mo period, during which females continued to oviposit in immature lateral heads throughout the flowering period of the thistles. Incubation periods in the field were determined by serial dissections of heads collected daily for $2 \mathrm{wk}$. Eclosion occurred about 1 wk to $10 \mathrm{~d}$ after oviposition. Ten eggs dissected from heads just after oviposition, placed on moist filter paper in covered Petri dishes, and held at a constant temperature of $27^{\circ} \mathrm{C}$, hatched after about $48 \mathrm{~h}$.

General Larval Habitus, Third Instar. Larvae of $P$. gentilis are typical of the Muscomorpha (i.e., they are white and maggotlike in shape). The average length of 12 fully grown larvae was $5.84 \pm$ $0.098 \mathrm{~mm}$. Most of the growth occurs in the third stadium. Newly eclosed third instars were only 2.8 $\mathrm{mm}$ long $(n=2)$; this represents over a two-fold increase in size. The gnathocephalon (Fig. 3) (terminology after Menees [1962]) is cone-shaped; the distal portion surrounding the mouth hooks comprises the lumen of the mouth. The mouth hooks of the third instar are tridentate and heavily sclerotized (Fig. 4, where the third tooth is behind and not visible). Between the mouth hooks is a laterally flattened, sclerotized, fanshaped projection we term the median oral lobe (Fig. 4 and 5, MOL). This structure has not been described heretofore for any Tephritidae as far as we can ascertain. It is comprised of a heavily sclerotized dorsal rib (diagrammed in Fig. 9, D RIB) which tapers to a point at the apex. Midway from the posterior end, two thin flanges project ventrad on either side to form the posterior margin of the ventral lobe (Fig. 9, V LOB). The lobe is lightly sclerotized, fleshy, laterally compressed, and has eight papillae along its ventral margin, each tipped with a small barb. The heavily sclerotized dorsal rib continues posteriorly in a $V$ shape and abuts the hypopharyngeal sclerite (Fig. 9). A bed of six sensory setae lies on the dorsal rib near the point of posterior attachment. The ventral muscle originates on the hypopharyngeal sclerite and inserts on the ventral flange of the dorsal rib. The median oral lobe moves independently of the mouth hooks in a very rapid, up-anddown motion; perhaps it helps the larva take in fluids after the mouth hooks shred plant tissues.

The dorsal margin of the gnathocephalon is comprised of several fleshy cowlshaped petals (Fig. 6, PET). On the dorsum of the gnathocephalon are two flattened anterior lobes (ANT L) and dorsal sensory organs (DSO) superior to the lobes (Fig. 6). Three sensory papillae lie on each anterior lobe; dorsally to ventrally, we have named them the lateral sensory organ (LSO), the pit sensory organ (PSO), and the terminal sensory organ (TSO) (Fig. 6).

The dorsal sensory organs are distinct from the anterior lobes, although they are closely associated. Chu \& Axtell (1971) and Singh \& Singh (1984) showed the dorsal organ of Musca domestica $\mathrm{L}$. and Drosophila melanogaster Meigen, respectively, to be distinct and separately innervated from the anterior lobe.

The prothoracic segment, although apparently smooth, is actually covered with $28(n=1)$ minute, flat papillae arranged in two rows which encircle the entire segment. Foote (1967) described "sensillae" on the tephritid Icterica seriata Loew. He, too, counted 28 of these papillae distributed around the entire prothorax.

The anterior spiracles are located on the posterior margin of the prothorax in third instars (Fig. 3). Each spiracle has seven to eight papillae.

The number of spiracular papillae in Tephritidae varies among species, among individuals of a species, and, sometimes, between sides of an individual (Phillips 1946). P. gentilis typically has eight papillae, but other species in this genus have more-P. culta typically has nine papillae (Ben- 

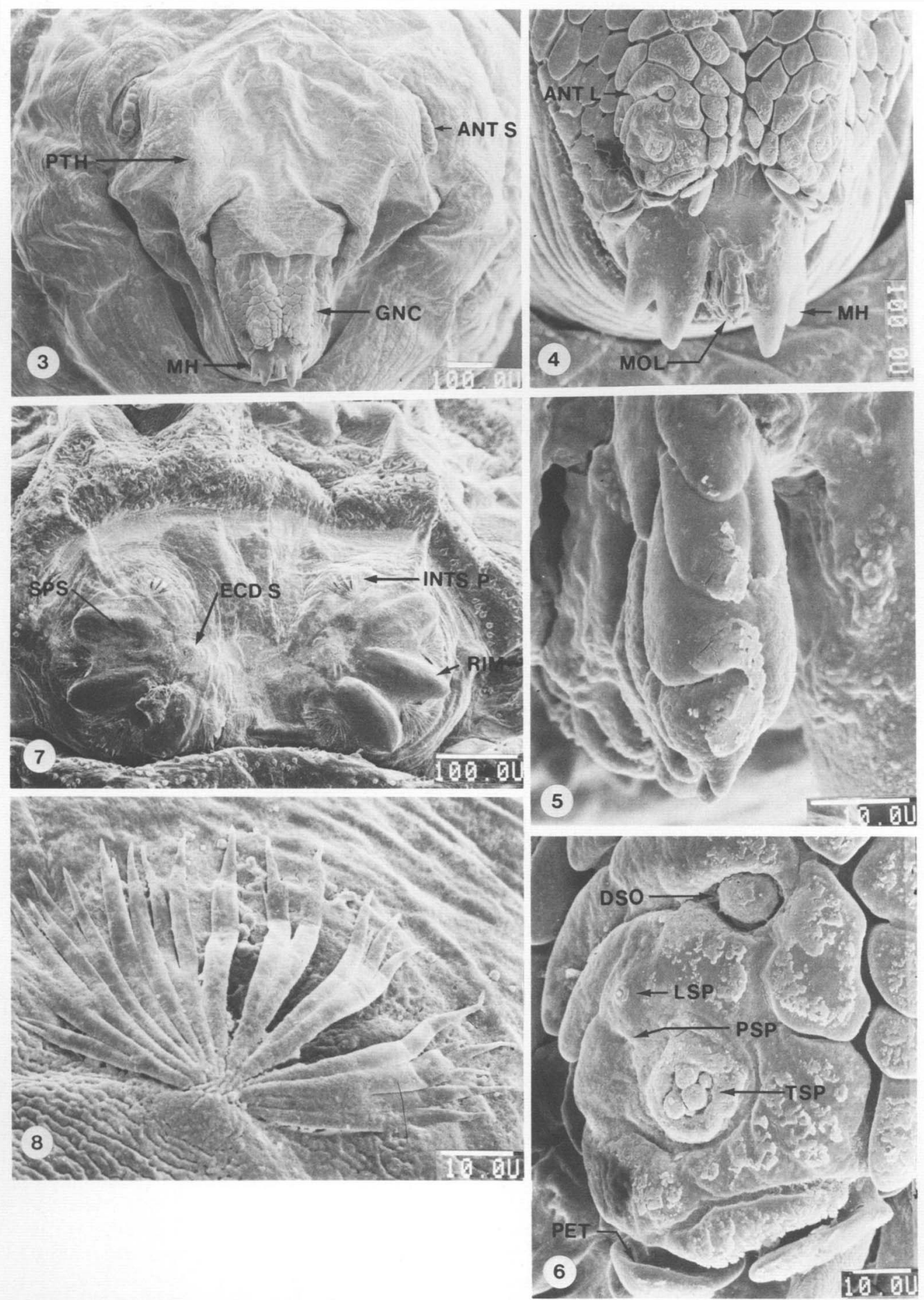

Fig. 3-8. Genera larval habitus, third instar. (3) Anterior end (75x). (4) Gnathocephalon (270x). (5) Detail of median oral lobe $(540 \times)$. (6) Right anterior lobe $(975 \times)$. (7) Posterior end of caudal segment (135x). (8) Interspiracular process $(1,200 \times)$. ANT L, anterior lobe; ANT S, anterior spiracle; DSO, dorsal sensory organ; ECD S, ecdysial scar; GNC, gnathocephalon; INTS P, interspiracular process; LSO, lateral sensory organ; MH, mouth hooks; MOL, median oral lobe; PET, petals, PSO, pit sensory organ; PTH, prothorax; RIM, rima; SPS, spiracular slit; TSO, terminal sensory organ. 


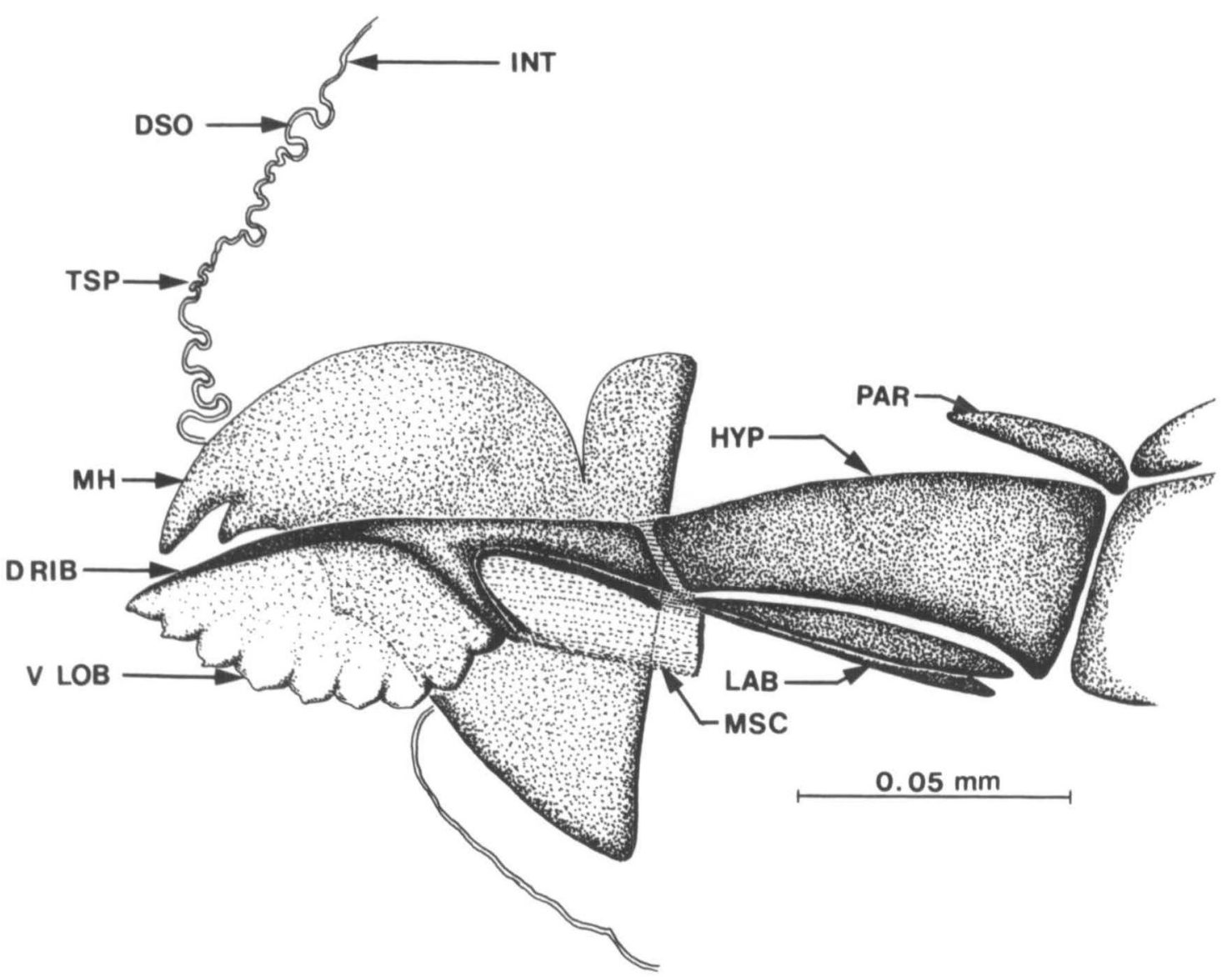

Fig. 9. Median oral lobe, left lateral view with left mouth hook removed. D RIB, dorsal rib; DSO, dorsal sensory organ; HYP, hypopharyngeal sclerite; INT, integument; LAB, labial sclerite, MH, mouth hook; MSC, muscle; PAR, parastomal bar; V LOB, ventral lobe.

jamin 1934, Phillips 1946) or fewer (e.g., P. forficula Benjamin has seven [Benjamin 1934]). Each following segment has a pair of small, fingerlike sensory papillae on its anterolateral margin. Each segment is circumscribed by rows of acanthate armatures on both the anterior and posterior margins. These are the segmental bands of dentition described by earlier workers as adaptations for locomotion or stabilization of the larva inside its food source (Phillips 1946). Each segment also is circumscribed by a transverse row of flattened papillae arranged in groups of 14 ventrally, 3 laterally, and 8 dorsally $(n=1)$.

The caudal segment is typical of that described by Phillips (1946) for Tephritidae. The two posterior segments bear many fingerlike papillae. The penultimate segment has dorsal, lateral, and ventral papillae, and the last segment has the fourdorsal, six-ventral arrangement of papillae.

The posterior spiracles are situated on the posterior portion of the last segment. Two lightly sclerotized spiracular plates each bear sclerotized, elongate oval rimae, four sets of branched interspiracular processes, and an ecdysial scar (Fig. 7). In life, the interspiracular process hairs extend from the body and may serve to keep debris away from the spiracular openings (Phillips 1946) (Fig. 8). The length of the longest hair was $0.04 \mathrm{~mm}$ and had a maximal width of $0.003 \mathrm{~mm}(n=1)$. Singh \& Singh (1984) showed each hair of the process to be innervated by a single dendrite in $D$. melanogaster.

The number and branching of the hairs increases with each instar; i.e., the first instar has a single, unbranched hair and the third instar has 9-16 highly branched or bifurcate hairs per tuft. The number of hairs and the branching vary among genera, species, and individuals, according to Snodgrass (1924) and Phillips (1946).

First Instar (Fig. 10). The lengths of 32 first instars averaged $1.03 \pm 0.009 \mathrm{~mm}$. They are elongate, cylindrical, and have a translucent integument through which the cephalopharyngeal skeleton is easily visible. Most of the cephalopharyngeal skeleton is sclerotized and black; however, the mouth hooks are less sclerotized, reddish brown, and bidentate. The median oral lobe is not welldefined; it appears as a laterally flattened structure between the teeth of the mouth hooks. 

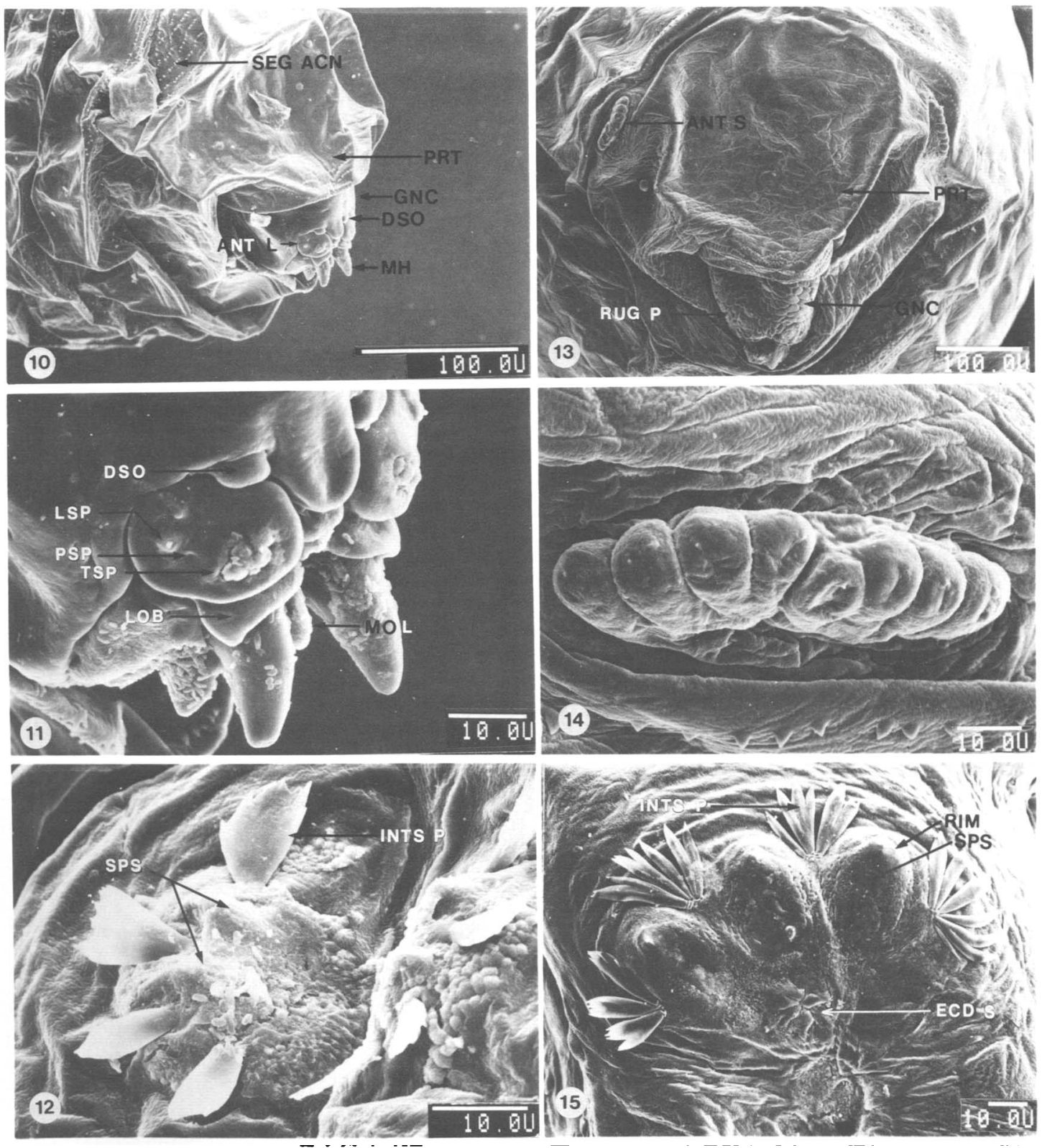

Fig. 10-15. First instar. (10) Anterior view $(252 \times)$. (11) Detail of gnathocephalon $(1,260 \times)$. (12) Detail of spiracular plates $(1,540 \times)$. Fig. 13-15. Second instar. (13) Anterior view $(140 \times)$. (14) Left prothoracic spiracle. (15) Detail of the left posterior spiracular plate $(658 \times)$. ANT L, anterior lobe; ANT S, anterior spiracle; DSO, dorsal sensory organ; ECD S, ecdysial scar; GNC, gnathocephalon; INTS P, interspiracular processes; LSP, lateral sensory papilla; MH, mouth-hooks; MOL, median oral lobe; PRT, prothorax; PSP, pit sensory papilla; RIM, rima; RUG P, rugose pads; SEG ACN, segmental acanthae; SPS, spiracular slits; TSP, terminal sensory papilla.

Directly above the mouth hooks is a pair of lobes (Fig. 11, LOB) which will develop into the petal structures in the later instars (Fig. 6, PET). Dorsal to these are the anterior lobes, on which are located the sensory papillae (Fig. 11), and directly above the anterior lobes are the dorsal sensory organs.

The posterior spiracles are composed of two slits in a $\mathrm{V}$ shape, the extended apex pointing medially.
The number of interspiracular processes is always four; in the first instar they comprise one unbranched hair each (Fig. 12). The largest hair $(n$ $=1$ ) measured $0.011 \mathrm{~mm}$ long and $0.009 \mathrm{~mm}$ wide.

Second Instar (Fig. 13). The second instar is opaque white and more barrelshaped than the first instar; its anterior end is more tapered and its posterior end more truncate. This instar showed a two- 


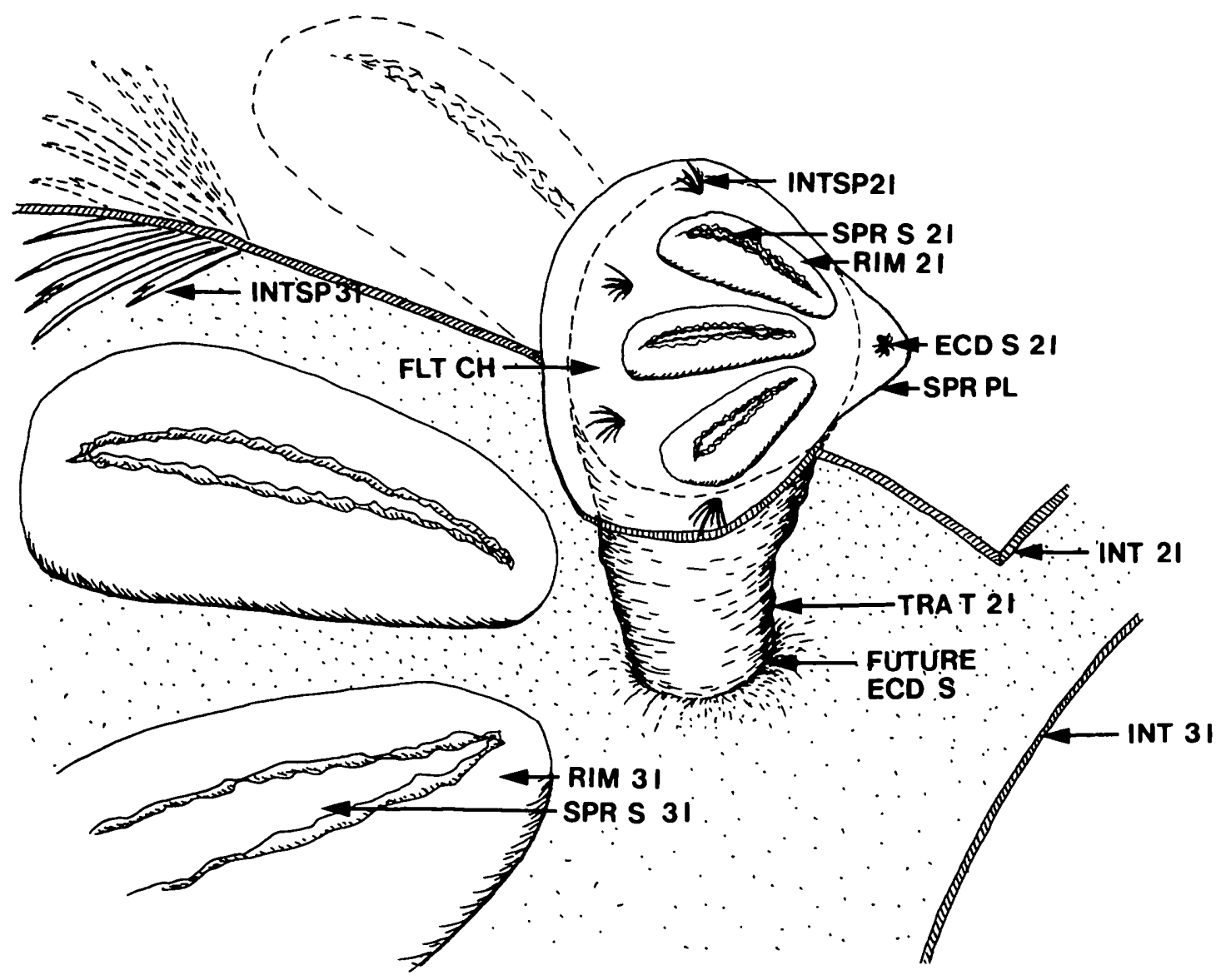

Fig. 16. Posterior view of molting second instar showing the position of spiracular slits and ecdysial scars. ECD S, ecdysial scar; FLT CH, felt chamber; INT, integument; INTS P, interspiracular process; RIM, rima; SPR PL, spiracular plate; SPR S, spiracular slit; TRA T, tracheal trunk; 2I, second instar; 3I, third instar.

fold increase in length; 10 larvae averaged $2.3 \pm$ $0.026 \mathrm{~mm}$ long. The mouth hooks are bidentate, darker, and more heavily sclerotized.

A major difference between the first and second instars is in the anterior portion of the gnathocephalon. The integument that surrounds the mouth hooks of the second instar is rugose and composed of many unevenly polygonal, flattened, and separate pads (Fig. 13, RUG P). These pads have not been described heretofore for any species of Tephritidae, although Varley (1937) and Steck \& Wharton (1986) drew rugose patterns in their illustrations of the "heads" of tephritid larvae. The function of these pads probably relates to the change in feeding habits of the second instar, which vacates a single floral tube and begins tunnelling laterally through several other floral tubes. The mouth hooks become more heavily sclerotized for use in shredding the floral tube tissues, and these pads may serve as conduits for the fluids obtained from the freshly torn tissue or as a mechanism to macerate these tissues further and extract the plant juices. Observation of living larvae showed the channels between the pads to be filled with fluids and the remnants of shredded tissues. Similar increases in surface area and armature were described using the SEM for the gall-former Chirosia betuleti Ringdahl (Anthomyiidae) by Aderkas \& Peterson (1987), who suggested their function involved further maceration of the tissues inside the gall.

The two most conspicuous changes involving the respiratory system are the addition of the prothoracic or anterior spiracles and the addition of a posterior spiracular opening. These modifications of the spiracular structure apparently facilitate respiration. The prothoracic spiracles are located dorsolaterally near the posterior margin of the prothorax and project fanlike from the body (Fig. 14). A single opening from the body wall continues as the trunk, which is topped with a row of seven to eight smaller papillae, each with an apical slit for the passage of air.

The number of posterior spiracular openings increases from two to three from the first to the second instar. The length of the largest slit in the second instar was $0.035 \mathrm{~mm}(n=1)$ (Fig. 15). The addition of a posterior spiracular slit was first reported in Tephritidae in Rhagoletis pomonella 

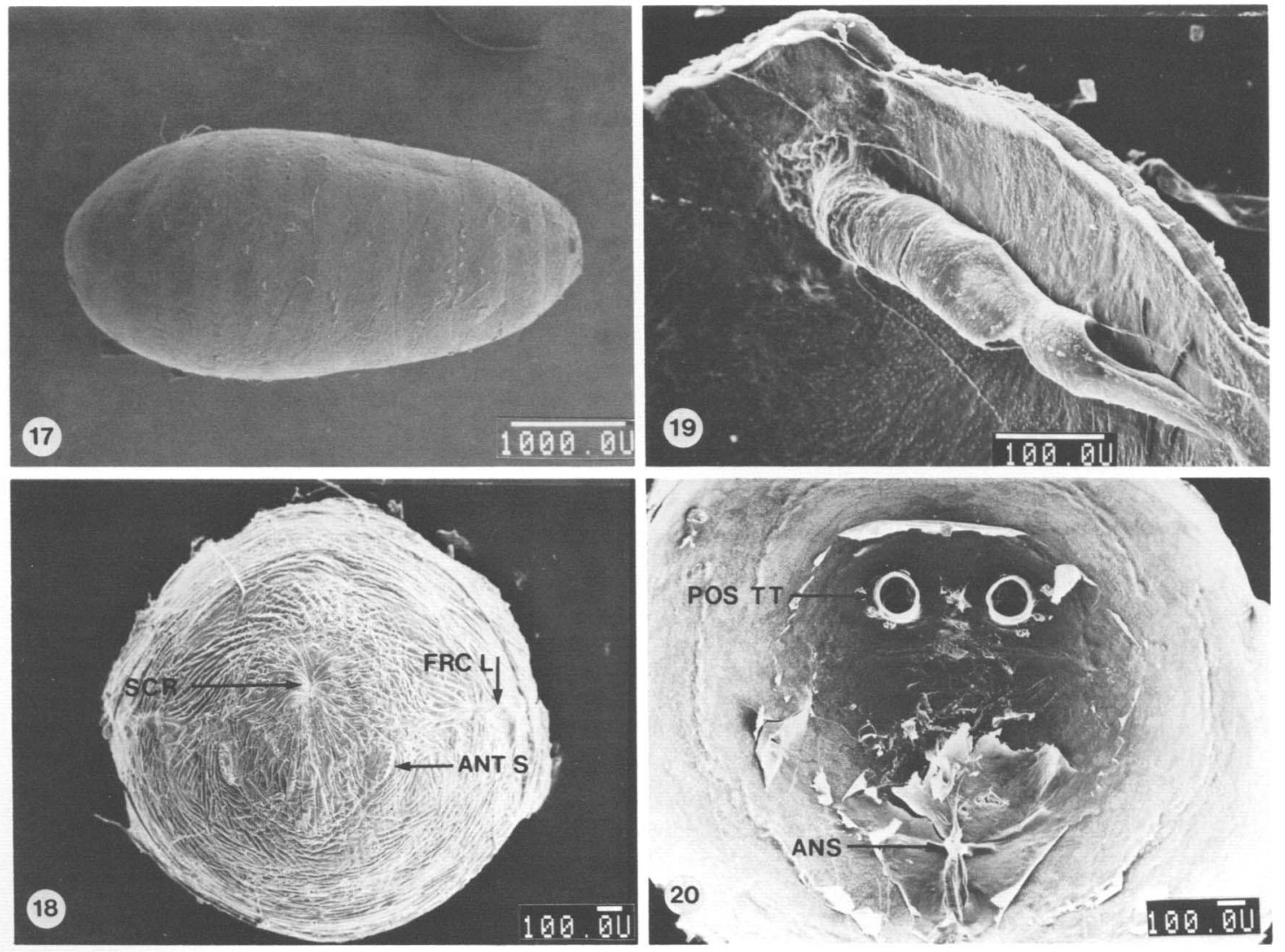

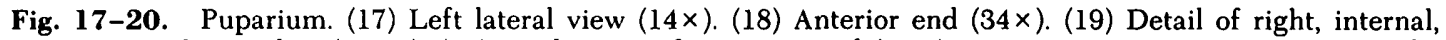
anterior spiracular trachea $(144 \times)$. (20) Inside view of posterior end $(38 \times)$. ANS, anus; ANT S, anterior spiracle; CPS S, cephalopharyngeal mouth scar; FRC L, fracture lines; POS TT, posterior tracheal trunks; SCR, mouth scar; TRA, trachea.

(Walsh) by Snodgrass (1924). Later work has shown this to be the case for most of the tephritids, and related families do conform to this pattern (cf. Snodgrass 1924; Benjamin 1934; Varley 1937; Keilin 1944; Phillips 1946; Martelli 1952; Dirlbek \& Dirlbek 1962; Allen \& Foote 1967; Foote 1967; Novak \& Foote 1968, 1975, 1980; Valley et al. 1969; Berube 1978; Steck 1984; White \& Clement 1987). The interspiracular processes of second instars also comprised increased numbers of hairs, ranging from four to seven (dorsal to ventral), reaching a length of $0.02 \mathrm{~mm}$.

Molting by a second instar removed from a capitulum was observed after its new cephalopharyngeal skeleton had been formed. The integument first split at its anterior end as the newly formed instar began peristaltic movements. Shedding the exuviae from most of the body lasted about $15 \mathrm{~min}$. The posterior spiracular slits of the second instar were one-fourth the size of those of the new third instar and were located toward the midline (Fig. 16). As the exuviae left the posterior end of the body, the linings of the tracheae were pulled from the body through a hole that became the ecdysial scar (Fig. 7, 16).
Puparium. The puparium of $P$. gentilis is barrelshaped and rounded at both ends (Fig. 17). The average maximal width and length of 82 puparia was $2.5 \pm 0.019$ and $5.2 \pm 0.03 \mathrm{~mm}$, respectively. Pupariation began with the larva turning its head up and away from the receptacle in the cavity formed during its last stages of feeding. The cephalon and most of the prothoracic segment invaginate into the anterior end of the body, leaving a small scar at the apex of the hardened puparium. The prothoracic spiracles are retained on the outer surface and project dorsally (Fig. 18). As the puparium hardens, it usually darkens progressively and becomes completely black; however, only the ends of some puparia darkened. This polar darkening had no apparent relationship to sex, multiple infestation in heads, time of year, capitulum size, or parasitism, and both types of puparia occurred together in the same heads.

The prepupa retained cuticular connections to the puparium at the mouth, anterior spiracles (Fig. 19), anus, and posterior spiracles (Fig. 20). Snodgrass (1924) described a row of nine stigmata along each lateral side of the puparium of $R$. pomonella that corresponded to the then-termed "fourth in- 


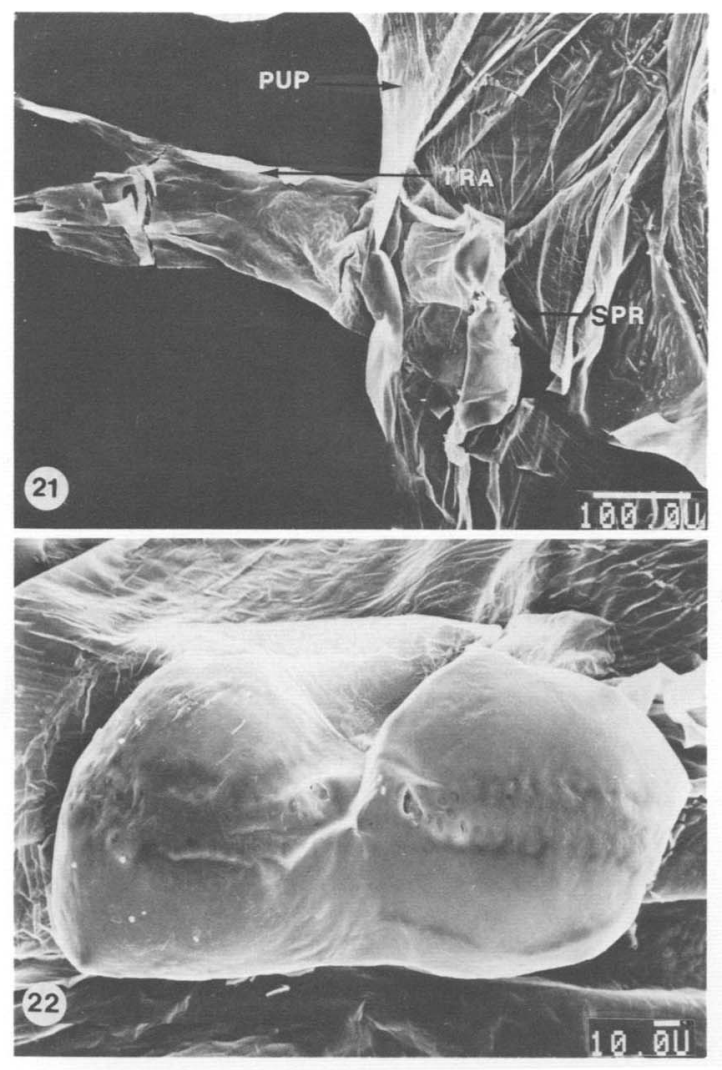

Fig. 21 and 22. Cast pupal exuviae. (21) Exuviae, trachea, and the bilobed spiracles $(112 \times)$. (22) Detail of spiracle $(308 \times)$. PUP, pupal exuvium; SPR, spiracle; TRA, trachea.

star" or prepupal lateral spiracles. In P. gentilis, the prepupa has lateral spiracles on each segment, but the corresponding connection to the puparium was not visible externally.

At pupation, all tracheal connections to the puparium are lost. The anterior and lateral spiracles and the linings of the tracheae are cast as part of the prepupal exuviae. The posterior tracheal linings are shed so they lie flat against the bottom of the interior of the puparium in an $\mathrm{S}$ shape. Snodgrass (1924) observed the same process in $R$. pomonella and determined that the larva sways its abdomen from side to side so that the linings are completely removed. The anterior spiracular tracheae lie against the puparium wall for a distance of about $0.5 \mathrm{~mm}$. The ends of these tubes were broken, but the taenidia helped maintain their tubular shape and an opening (Fig. 19). There is no connection between the puparium and the newly formed pupa but, as Snodgrass (1924) described for $R$. pomonella, the pupa of $P$. gentilis shrinks away from the prepupal exuviae, and air is brought into this space through the broken tubes of the anterior spiracles. The pupa respires through large, bilobed, partially sclerotized thoracic spiracles which can be seen as part of the cast pupal exuviae (Fig. 21 and 22).

\section{Discussion}

As Steck \& Wharton (1986) discussed, detailed descriptions of tephritid larvae are rare; rarer still are descriptions of eggs and early instars. The method for viewing larvae described by Phillips (1946), which involved clearing in $\mathrm{KOH}$, may have reduced the ability to see certain structures. By using the methods described to prepare specimens for SEM, all larval structures were preserved, and all three instars could be followed to study their development, the homology of structures, and their implications for systematics.

The sensory structures on the gnathocephalon of the larvae of higher Diptera have been described in Anthomyiidae (Aderkas \& Peterson 1987), Calliphoridae (Ludwig 1949), Drosophilidae (Singh \& Singh 1984), Muscidae (Bolwig 1946; Chu \& Axtell 1971, 1972a,b), Syrphidae (Hartley 1962, Roberts 1971, Maier 1978), and Tephritidae (Snodgrass 1924, 1953). The basic structure of the sensory organs in larvae of these families apparently is very similar. The dorsal sensory organ is usually a onesegmented papilla set into a ring or collar. The terminal sensory organ comprises five or six smaller papillae set into a ring or collar; there is disagreement as to what these structures represent. The dorsal sensory organ has been called the antenna, and the terminal sensory organ on the anterior lobes has been called the maxillary palpi, suggesting homology with adult or brachyceran larval structures (Teskey 1981). Snodgrass (1953) did not interpret these structures in this way, based on embryological evidence by Pratt (1897, 1900), Snodgrass (1924), and Robertson (1936), thus perpetuating a longstanding argument as to what these structures represent. More recently, Hartley (1962) and Roberts (1971) gave nervous innervation as evidence for homology to imaginal structures, but the nerves cited do not have associations with imaginal discs, and no embryological evidence is shown.

The anterior lobe of $P$. gentilis contains three distinct types of sensory structures. These structures also have been shown in Anastrepha ludens (Loew) by Carroll \& Wharton (1989), and in seven other species in six genera of nonfrugivorus tephritids (D.H., unpublished data). The median oral lobe also occurs in these seven species but does not occur in A. ludens (Carroll \& Wharton 1989), Ceratitis capitata (Wiedemann), and Dacus dorsalis Hendel (D.H., unpublished data). All these structures show morphogenesis between instars, complete development culminating in the third instar.

To consider these structures as a "logical further development" of the features of the orthorrhaphous brachyceran larvae, as suggested by Teskey (1981), based on the "trends" postulated by Cook (1949), one must ignore the fact that ". . . a series of connectant groups showing the gradual evolu- 
tion of the cephalopharyngeal skeleton and associated structures (our italics) is lacking ..." (Teskey, 1981, 74). Our findings, together with those of Menees (1962), Chu \& Axtell (1971, 1972a,b) and Singh \& Singh (1984), suggest that these larval sensory structures and mouthparts should not be so readily homologized with imaginal or brachyceran larval structures.

\section{Acknowledgment}

We thank D. W. Ricker for technical assistance with this research; G. Gordh and M. Moratorio for their assistance with the SEM, advice, encouragement, and helpful discussions; and T. S. Bellows, F. L. Blanc, R. H. Foote, and W. J. Turner for their reviews of earlier drafts of this manuscript.

\section{References Cited}

Aderkas, P. von \& B. V. Peterson. 1987. Chirosa betuleti (Ringdahl) (Diptera: Anthomyiidae) a gallformer on the ostrich fern, Matteucia struthiopteris, with notes on other insect-fern associates. Proc. Entomol. Soc. Wash. 89(3): 532-547.

Allen, E. J. \& B. A. Foote. 1967. Biology and immature stages of three species of Otitidae (Diptera) which have saprophagous larvae. Ann. Entomol. Soc. Am. 60: 826-836.

Benjamin, F. H. 1934. Descriptions of some native trypetid flies with notes on their habits. USDA Technical Bulletin 401.

Berube, D. E. 1978. Larval descriptions and biology of Tephritis dilacerata (Diptera: Tephritidae), a candidate for the biocontrol of Sonchus arvensis in Canada. Entomophaga 23(1): 69-82.

Bolwig, N. 1946. Senses and sense organs of the anterior end of the housefly larva. Vidensk. Medd. Dan. Naturhist. Foren. 109: 81-217.

Carroll, L. E. \& R. A. Wharton. 1989. Morphology of the immature stages of Anastrepha ludens (Diptera: Tephritidae). Ann. Entomol. Soc. Am. 82: 201214.

Cavender, G. L. \& R. D. Goeden. 1984. The life history of Paracantha cultaris (Coquillett) on wild sunflower, Helianthus annuus L. ssp. lenticularis (Douglas) Cockerell, in southern California (Diptera: Tephritidae). Pan-Pac. Entomol. 60: 213-218.

Chu, I-Wu \& R. C. Axtell. 1971. Fine structure of the dorsal organ of the house fly larva, Musca domestica L. Z. Zellforsch. 117: 17-34.

1972a. Fine structure of the terminal organ of the house fly larva, Musca domestica L. Z. Zellforsch. Mikrosk. Anat. 127: 287-305.

1972b. Fine structure of the ventral organ of the house fly larva, Musca domestica L. Z. Zellforsch. Mikrosk. Anat. 130: 489-495.

Cook, E. F. 1949. The evolution of the head in the larvae of the Diptera. Microentomology 14: 1-57.

Dirlbek, K. \& J. Dirlbek. 1962. Beitrag zur Kenntnis einiger Bohrfliegenlarven. Beitr. Entomol. 12: 336344.

Foote, B. A. 1967. Biology and immature stages of fruit flies: the genus Icterica (Diptera: Tephritidae). Ann. Entomol. Soc. Am. 53(1): 121-125.

Goeden, R. D. \& D. W. Ricker. 1986. Phytophagous insect faunas of the two most common native Cirsium thistles, C. californicum and C. proteanum, in southern California. Ann. Entomol. Soc. Am. 79: 953-962.

Hartley, J. C. 1962. The cephalopharyngeal apparatus of syrphid larvae and its relationship to other Diptera. Proc. Zool. Soc. Lond. 141: 261-280.

Keilin, D. 1944. Respiratory systems and respiratory adaptations in larvae and pupae of Diptera. Parasitology 36: 1-66.

Ludwig, C. E. 1949. Embryology and morphology of the larval head of Calliphora erythrocephala Meigen. Microentomology 14: 75-111.

Maier, C. T. 1978. The immature stage and biology of Mallota postica (Fabricius) (Diptera: Syrphidae). Proc. Entomol. Soc. Wash. 80: 424-440.

Martelli, M. 1952. Reperti sulla Terrellia fuscicornis (Loew) (Diptera: Tephritidae). Redia 33: 221-286.

Menees, J. H. 1962. The skeletal elements of the gnathocephalon and its appendages in the larvae of higher Diptera. Ann. Entomol. Soc. Am. 55: 607-618.

Nation, J. L. 1983. A new method using hexamethyldisilizane for preparation of soft insect tissues for scanning electron microscopy. Stain Technol. 58: 347351.

Novak, J. A. \& B. A. Foote. 1968. Biology and immature stages of fruit flies: Paroxyna albiceps (Diptera: Tephritidae). J. Kans. Entomol. Soc. 41: 607618.

1975. Biology and immature stages of fruit flies: the genus Stenopa (Diptera: Tephritidae). J. Kans. Entomol. Soc. 48: 42-52.

1980. Biology and immature stages of fruit flies: the genus Eurosta (Diptera: Tephritidae). J. Kans. Entomol. Soc. 53: 205-219.

Phillips, V. T. 1946. The biology and identification of trypetid larvae (Diptera: Tephritidae). Memoirs of the American Entomological Society 12.

Pratt, H. S. 1897. Imaginal discs in insects. Psyche 8: $15-36$.

1900. The embryonic history of imaginal discs in $\mathbf{M e -}$ lophagus ovinus $\mathrm{L}$. together with an account of the earlier stages in the development of the insect. Proc. Boston Soc. Nat. Hist. 29: 241-272.

Roberts, M. J. 1971. The structure of the mouthparts of some calypterate dipteran larvae in relation to their feeding habits. Acta Zool. Stockh. 52: 171-188.

Robertson, C. W. 1936. The metamorphosis of Drosophila melanogaster, including an accurately timed account of the principle morphological changes. J. Morphol. 59: 351-399.

Sabatini, D. D., K. Bensch \& R. J. Barnett. 1963. The preservation of cellular ultrastructure and enzymatic activity by aldehyde fixation. J. Cell. Biol. 17: 19-58.

Sher, S. A. \& A. H. Bell. 1975. Scanning electron micrographs of the anterior region of some species of Tylenchoidea (Tylenchida: Nematoda). J. Nematol. 7: 69-83.

Singh, R. N. \& K. Singh. 1984. Fine structure of the sensory organs of Drosophila melanogaster Meigen larva (Diptera: Drosophilidae). Int. J. Insect Morphol. Embryol. 13: 255-273.

Snodgrass, R. E. 1924. Anatomy and metamorphosis of the apple maggot, Rhagoletis pomonella Walsh. J. Agric. Res. Wash. D.C. 28: 1-36.

1953. The metamorphosis of a fly's head. Smithsonian Miscellaneous Collections, vol. 122, no. 3.

Steck, G. J. 1984. Chaetostomella undosa (Diptera: Tephritidae): biology, ecology, and larval description. Ann. Entomol. Soc. Am. 77: 669-678.

Steck, G. J. \& R. A. Wharton. 1986. Description of 
immature stages of Eutreta (Diptera: Tephritidae). J. Kans. Entomol. Soc. 59: 296-302.

Teskey, H. J. 1981. Morphology and terminologylarvae, pp. 65-88. In J. F. McAlpine et al. [eds.], Manual of Nearctic Diptera, vol. 1. Research Branch, Agriculture Canada, Monograph 27, Ottawa, Canada.

Valley, C., J. A. Novak \& B. A. Foote. 1969. Biology and immature stages of Eumetopiella rufipes (Diptera: Otitidae). Ann. Entomol. Soc. Am. 62: 227-234.

Varley, G. C. 1937. The life-history of some trypetid flies, with descriptions of the early stages (Diptera) Proc. R. Entomol. Soc. Lond. Ser. A Gen. Entomol. 12: 109-122.

White, I. M. \& S. L. Clement. 1987. Systematic notes on Urophora (Diptera: Tephritidae) species associated with Centaurea solstitialis (Asteraceae, Cardueae) and other Palaearctic weeds adventive in North America. Proc. Entomol. Soc. Wash. 89: 571-606.

Received for publication 21 November 1988; accepted 18 May 1989. 